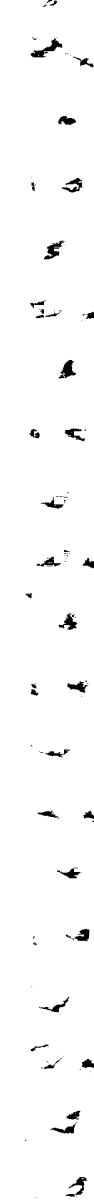

$$
-
$$$$
2
$$$$
7
$$$$
\rightarrow
$$$$
\text { ฟ }
$$$$
-*
$$$$
=
$$$$
+
$$

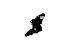$$
4
$$

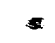$$
\checkmark
$$$$
4
$$$$
\text { s. }
$$$$
\begin{aligned}
& \text { Doctors Ought to } \\
& \text { Care (DOC), } \\
& \text { Department of } \\
& \text { Family Medicine, } \\
& \text { Baylor College of } \\
& \text { Medicine, 5510 } \\
& \text { Greenbriar, Houston, } \\
& \text { Texas 77005, USA } \\
& \text { A Blum }
\end{aligned}
$$

\section{DOC's Deck-O-Butts trading cards: using humour to change youth attitudes about tobacco}

\author{
Alan Blum
}

For children throughout the world, the hobby of card collecting is becoming increasingly popular. From the neighbourhood corner shop to large department stores, dozens of varieties of cards are on display. Countless collectors' magazines are published monthly, and card shows draw thousands of hobbyists.

Most card series are related to sports, but examples of non-sports series issued in the past year include Return of the Flintstones, Lift-off (about astronauts and space), Ford Mustang 30th Anniversary Collection, Canada Steam Locomotives, East Coast Lighthouses, Santa Around the World, and World War II 50th Anniversary. Among the most popular series are adventure and action themes such as Mighty Morphin Power Rangers, Spiderman, Marvel Masterpieces Superheroes, and Star Trek Master Series. Several series based on irreverent cartoon characters have attracted a wide teenage following, including The Simpsons, Ren \& Stimpy, and Beavis and Butthead.

Although it has been more than half a century since cigarette company trading cards

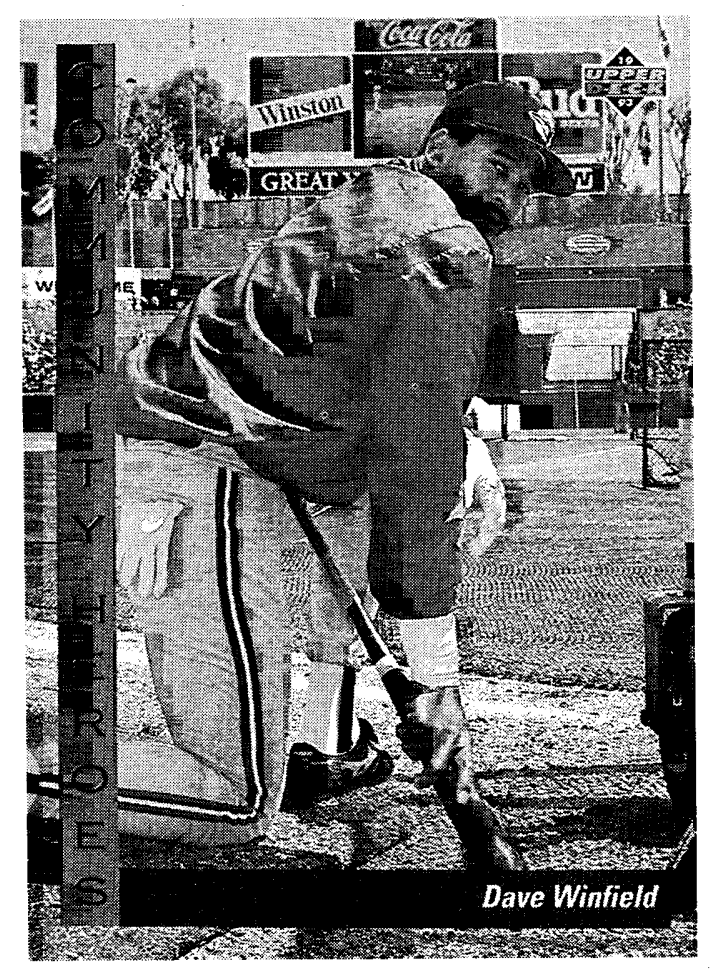

Figure 1 Trading card for baseball star Dave Winfield, posing in front of a Winston sign. occupied the hobby's centre stage, ${ }^{1}$ tobacco has maintained a pernicious presence even in cards clearly aimed at young collectors. In 1993, 9 year old David Blum of Houston, Texas, noticed that on the baseball card of the American player Dave Winfield, the popular slugger was posed in front of a stadium billboard advertising RJ Reynolds Tobacco Company's Winston cigarettes (figure 1). David found other examples of baseball cards featuring players with cheeks seemingly full of chewing tobacco (figure 2) and one card with a sign for Philip Morris' Marlboro cigarettes (figure 3). Series produced by the magazine Sports Illustrated for Kids have included cards with Philip Morris's Virginia Slims and Marlboro logotypes (figure 4). In 1994 RJ Reynolds issued its own set of Winston auto racing cards (figure 5).

After David and his then 7 year old brother Sammy found five cards of a series of 100 Marvel Masterpieces in which Superheroes were shown smoking (figure 6), Sammy wrote a letter to the editor of the New England fournal of Medicine $(1994 ; 330$ : 1321) in which

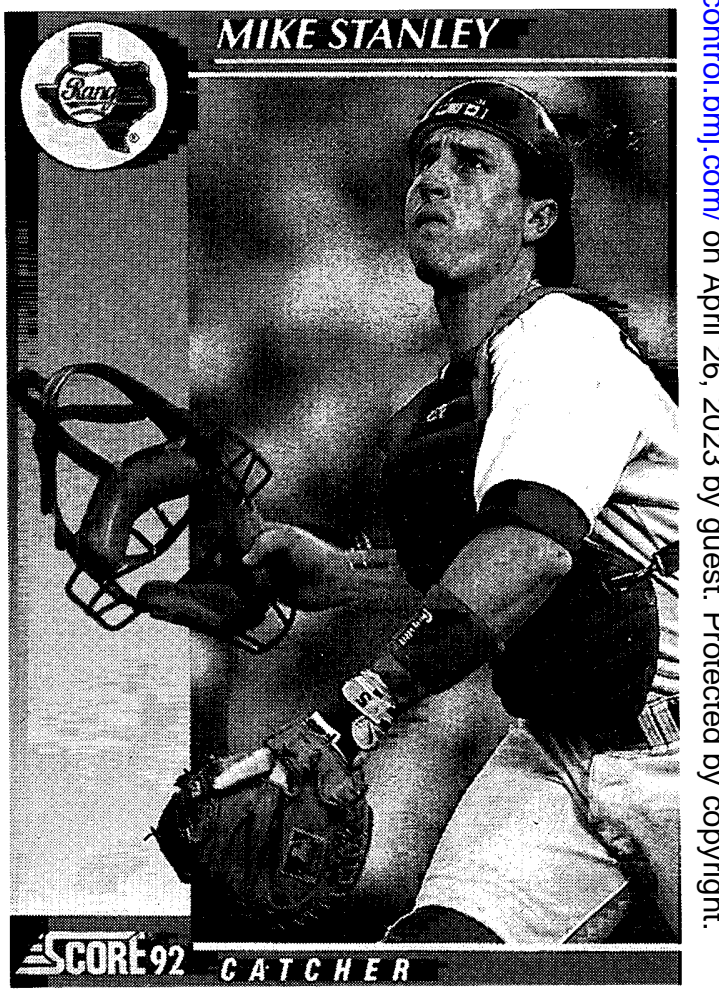

Figure 2 Trading card for baseball player Mike

Stanley, with a cheek seemingly full of chewing tobacco. 


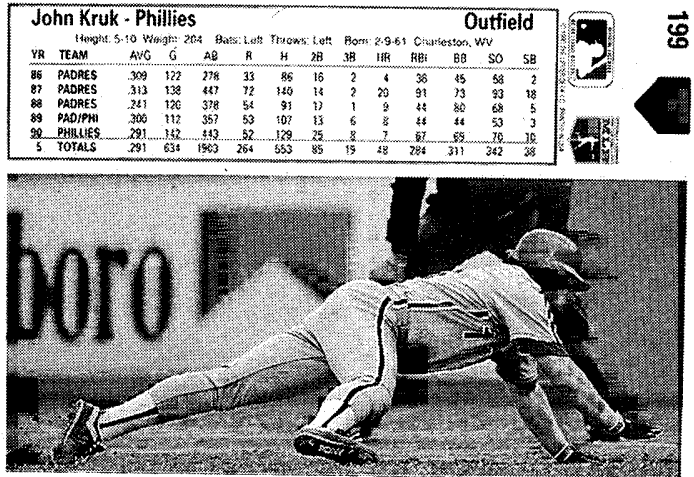

Figure 3 Trading card for baseball star fohn Kruk, diving in front of a Marlboro sign.
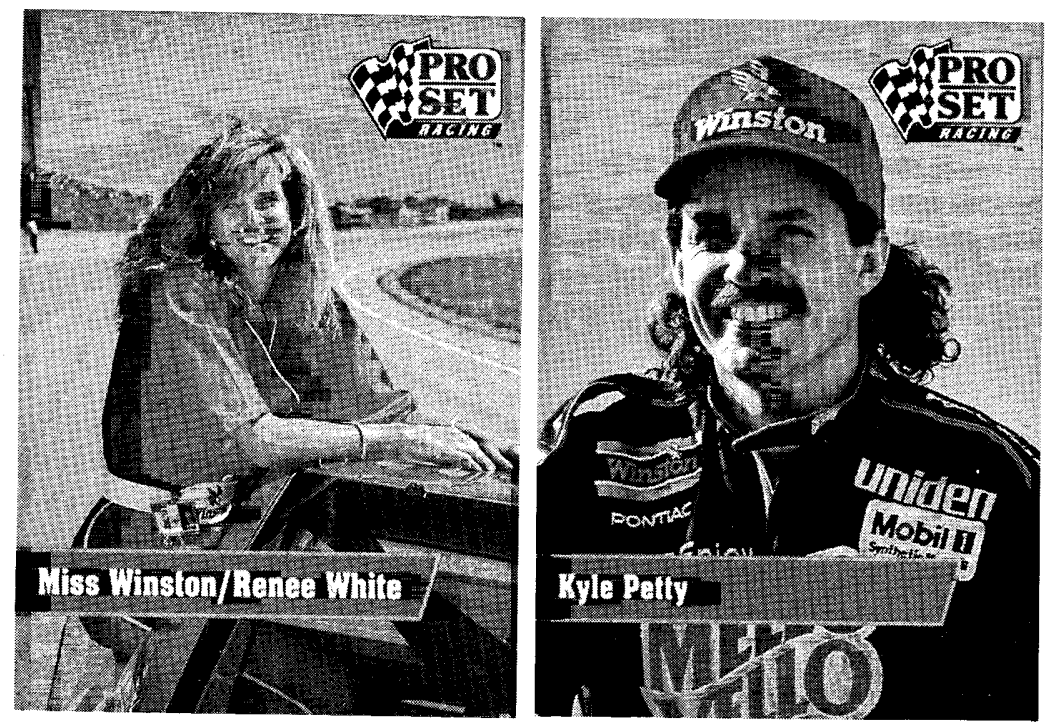

Figure 5 In addition to Rf Reynolds' Winston auto racing cards, several trading card series such as the above by Pro Set Racing have featured tobacco brand logos.

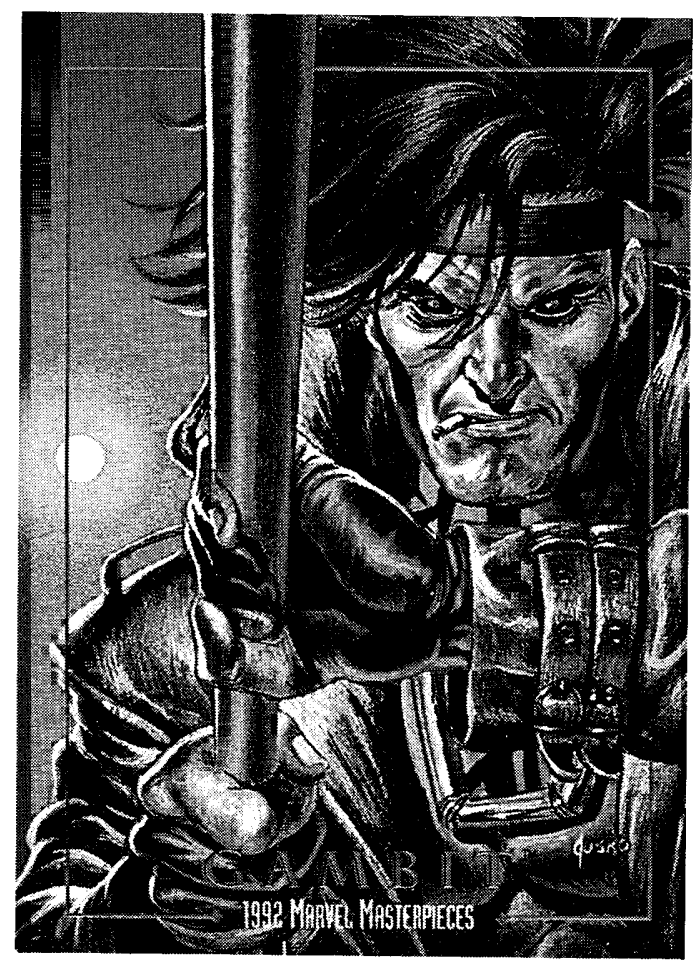

Figure 6 A Marvel Superhero trading card.

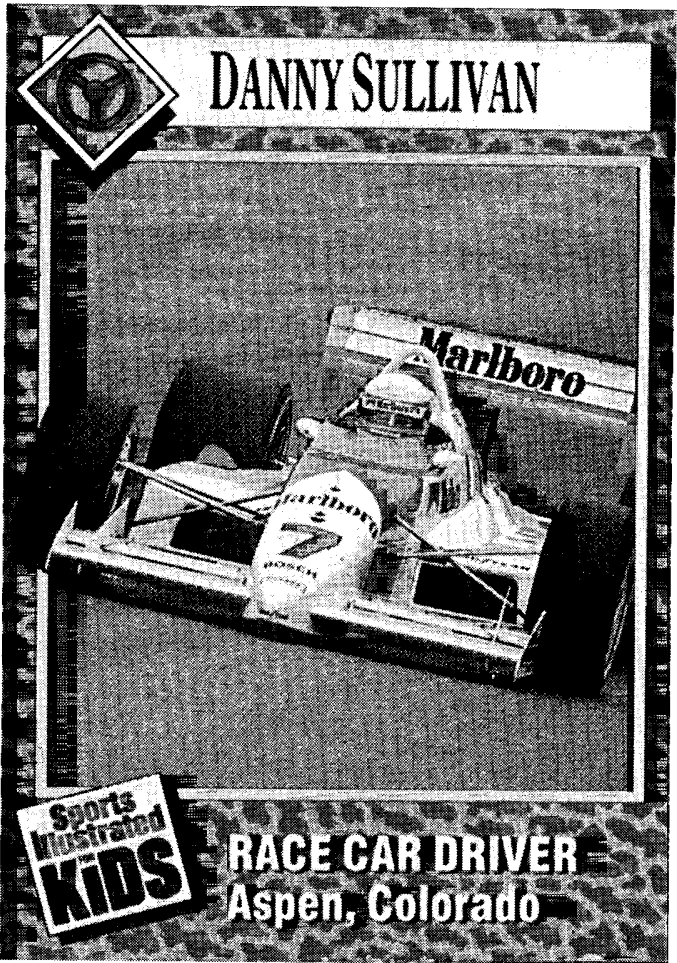

Figure 4 Danny Sullivan's Marlboro race car, featured on a Sports Illustrated for Kids trading card.

he asked, "Why do they make cards for kids that show people smoking?" The embarrassed card company, part of the conglomerate Marvel Entertainment Group, agreed to keep smoking materials out of future trading card collections.

A few attempts have been made to capitalise on the popularity of both sports and card collecting among children by producing cards with health related or other socially responsible messages. For example, the National Football League in the USA issued a card with a football player urging students, "Stay in School". The American Cancer Society produced a few different cards of baseball players beneath the headline, "Strike Out Tobacco!" (figure 7).

In 1993 the health promotion group Doctors Ought to Care (DOC), with the support of the Thrasher Research Foundation, sought to create a series of cards with the offbeat, antiauthoritarian humour of adolescents as a means of encouraging ridicule of the tobacco industry and its most popular cigarette brands. "DOC's Deck-O-Butts: Fakes, Facts, and Farts", consists of 21 cards that aim at undermining brand names and changing attitudes. Behind the gross humour (the titles of two of the most well received cards are "Phlegm Hackers" and "The Sound of $\mathrm{Mu}$ cus") is a strategy designed to familiarise teenagers with the names of the tobacco companies " Cancer's 7 Warning Signs" is the theme of one card), the ingredients of cigarettes, tobacco sponsored sports, techniques used to target women and minority groups, and tobacco-caused diseases, disabilities, and cosmetic side effects (see figure 8).$$
=
$$

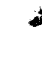$$
\geqslant
$$$$
y
$$$$
4
$$$$
\text { s }
$$

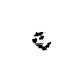

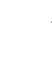$$
\checkmark
$$

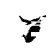$$
=
$$$$
2
$$

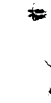$$
\text { b }
$$$$
-
$$$$
+
$$$$
\neq
$$$$
c
$$$$
\text { ? }
$$$$
\nabla
$$

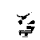

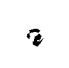




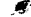$$
=
$$$$
\mathbf{x}
$$

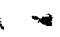$$
\checkmark
$$$$
+
$$$$
\checkmark
$$$$
-4
$$

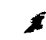$$
4
$$

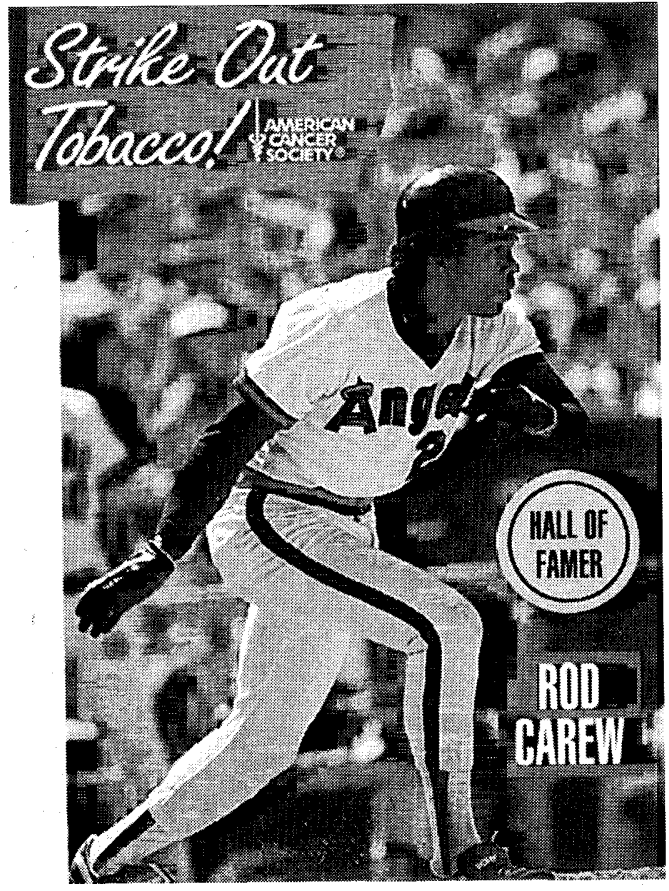

Figure 7 An American Cancer Society trading card.

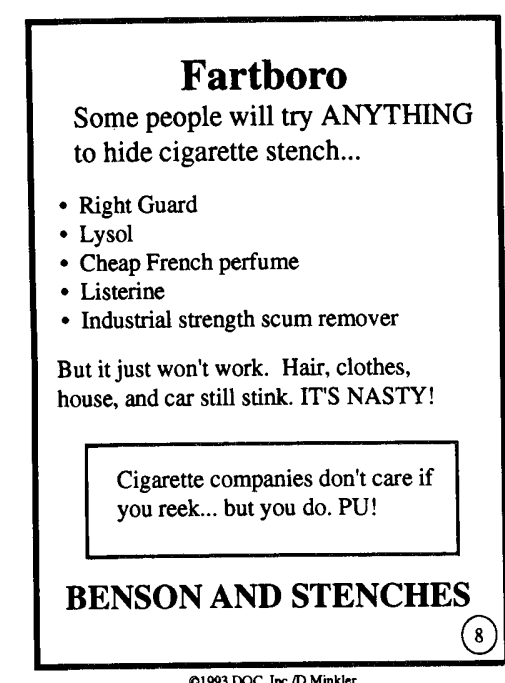

$01093 \mathrm{DOC}$ loc D Minker

\section{THE SOUND OF MUCUS}

The heads of cigarette companies all say that smoking can't even cause a cough. Then why don't they smoke?

The truth is, someone who smokes wakes up every morning to...

- COUGH

- haCK

- HURL

CHUNKS OF

\section{- PHLEGM}

- SNOT

- BOOGERS

Girl kissing boy:

"Oops. I think I swallowed your gum."

Boy to girl:

"No, I just cleared my throat."
Unlike traditional health education interventions, which are designed solely to impart information about the health hazards of smoking, Deck-O-Butts explores the gamut of tobacco issues through the use of humour. The technique addresses tobacco use among young people as a consumer issue as well as a health issue. This concept is based on the fact that children are "branded" through advertising and promotion for specific brand name products at a very young age. In spite of established research showing that tobacco product logotypes and mascots are readily recognised by children, traditional health education efforts have all but avoided using brand names.

Preliminary results of surveys of middle school students (aged 11-14) who have traded the cards suggest that this uninhibited approach can give adolescents permission to laugh at the real authority figures in their lives, namely the promoters of tobacco products and their brand names. Indeed, the two most popular cards by far are those that satirise the two best selling brands among teenagers: Camel and Marlboro (see cover).

All too many efforts to educate young people about tobacco have relied on pamphlets, posters, and preaching on the dangers of nicotine. In the future, strategies must increasingly focus on observing and listening to teenagers in their natural mass media saturated habitat and learning from them about the important issues and images in their world.

1 Blum A. Cigarette cards - irony in propaganda. Tobacco Control $1995 ; 4$ : 117-8.

Figure 8 The reverse side of two Deck-O-Butts trading cards shown on the cover:

"Stink Bomb" (left) and "Hackers" (right).

\section{Note to readers}

We hereby solicit your ideas and contributions for future covers of Tobacco Control. Like previous covers, we would like future covers to be colourful and creative - with a tobacco control theme. Original artwork, anti-tobacco posters, photographs, and cartoons may all be considered. Material with an international flavour would be particularly desirable. A cover essay will generally appear in each issue to provide appropriate background information and commentary on the cover.

Please send ideas and submissions (original or high quality, camera-ready photographs) to the editor at the address on the inside front cover. - ED 